\title{
Characteristics of Microstructure in Ultrahigh Carbon Steel Produced during Friction Stir Welding
}

\author{
Yutaka S. SATO, ${ }^{1)}$ Hideaki YAMANOI, ${ }^{1)}$ Hiroyuki KOKAWA ${ }^{1)}$ and Tadashi FURUHARA ${ }^{21}$ \\ 1) Department of Materials Processing, Graduate School of Engineering, Tohoku University, 6-6-02 Aramaki-aza-Aoba, Aoba- \\ ku, Sendai 980-8579 Japan. $\quad$ 2) Institute for Materials Research, Tohoku University, 2-1-1 Katahira, Aoba-ku, Sendai 980- \\ 8577 Japan.
}

(Received on August 31, 2007; accepted on November 8, 2007)

\begin{abstract}
Ultrahigh carbon steels containing 1 to $2 \mathrm{wt} \% \mathrm{C}$ have very poor fusion-weldability, but exhibit high strength-ductility balance, good wear resistance and superplasticity at high temperatures, when a microduplex structure consisting of a fine ferrite grain structure with a uniform distribution of spheroidized cementite is formed. Thus, ultrahigh carbon steels with the microduplex structure show promise for use in construction. In the present study, two kinds of initial microstructure, a fully pearlitic structure and a microduplex structure, were produced in an ultrahigh carbon steel with $1 \mathrm{wt} \% \mathrm{C}$ by different thermal treatments, this steel then being subjected to friction stir welding (FSW) at different rotational speeds using a polycrystalline cubic boron nitride tool. The feasibility of friction stir welding for ultrahigh carbon steel and the effect of welding parameters and initial microstructure on the residual microstructure characteristics of the weld were systematically examined. FSW successfully yielded defect-free welds in the ultrahigh carbon steel at all welding parameters employed. All welds exhibited very high hardness in the weld center due to the martensitic transformation. The difference in characteristics of the martensitic structure among the welds was negligible, but the austenite substructure was affected by the rotational speed. Microstructural development of various regions in the welds was reasonably accounted for by the friction stir welding process, the thermal stability of the initial microstructure and the solid-state transformation during cooling cycle of FSW.
\end{abstract}

KEY WORDS: ultrahigh carbon steel; friction stir welding; microstructure; hardness; welding parameters.

\section{Introduction}

Ultrahigh carbon steels containing 1 to $2 \mathrm{wt} \% \mathrm{C}$ are hypereutectoid steels. ${ }^{1)}$ They exhibit high strength-ductility balance, good wear resistance and superplasticity at high temperatures, when a fine ferrite $(\alpha)$ grain structure with a uniform distribution of spheroidized cementite $\theta\left(\mathrm{Fe}_{3} \mathrm{C}\right)$, i.e. an $(\alpha+\theta)$ microduplex structure, is formed through adequate thermal treatment. ${ }^{2-4)}$ Therefore, ultrahigh carbon steels with the microduplex structure have attracted attention as a structural material, although it is known that fusion-weldability of ultrahigh carbon steel is extremely low because solidification and/or hydrogen cracking often occur in these steels during fusion welding processes. ${ }^{5-7}$ )

Friction stir welding (FSW) is a solid-state joining process developed and patented by The Welding Institute (TWI) in the UK in 1991. ${ }^{8-10)}$ Since its inception, FSW had been restricted to lower melting temperature materials, such as aluminum $(\mathrm{Al})$, magnesium $(\mathrm{Mg})$ and copper $(\mathrm{Cu})$ alloys, ${ }^{11-15)}$ due to a lack of available tools for high melting temperature materials. Recently, several welding tools with high temperature strength and wear resistance have been developed. ${ }^{16)}$ Various papers on FSW of steels, such as carbon steels having carbon contents up to $0.70 \mathrm{wt} \%,{ }^{17-19)}$ mild steel, ${ }^{20)}$ DH36 steel, ${ }^{21)}$ pipeline steel ${ }^{22)}$ and stainless steels, ${ }^{23-28)}$ have been also published, showing that FSW can produce defect-free welds in these steels even if the fusionweldability is poor.

FSW of ultrahigh carbon steel with $1 \mathrm{wt} \% \mathrm{C}$ has been previously investigated by Sato et al. ${ }^{29)} \mathrm{FSW}$ successfully produced defect-free welds in ultrahigh carbon steel, the weld center having a hard microstructure formed through martensitic transformation due to the high hardenability of the ultrahigh carbon steel. The microstructural evolution of the ultrahigh carbon steel during FSW was also described. However, the effect of welding parameters on the microstructural characteristics in welds has not been systematically examined, although it is likely that the microstructural evolution during FSW strongly depends on such parameters.

In the present study, two kinds of initial microstructure were produced in the ultrahigh carbon steel containing $1.0 \mathrm{wt} \% \mathrm{C}$ by different thermal treatments: a pearlitic structure and a microduplex structure consisting of an $\alpha$ matrix and spheroidized $\theta$. FSW was then applied to these structures at different rotational speeds using a polycrystalline cubic boron nitride (PCBN) tool. The objective of this study is to systematically clarify microstructural character- 
istics in friction stir welded ultrahigh carbon steel at different welding parameters.

\section{Experimental Procedures}

The base material used in this study was commercial bearing steel (SUJ2: $\mathrm{Fe}-1.02 \mathrm{wt} \% \mathrm{C}-0.24 \mathrm{wt} \% \mathrm{Si}-0.37 \mathrm{wt} \%$ $\mathrm{Mn}-1.42 \mathrm{wt} \% \mathrm{Cr}$ ), $2.3 \mathrm{~mm}$ in thickness. $\mathrm{A}_{1}$ and $\mathrm{A}_{\mathrm{cm}}$ temperatures determined by dilatometry measurement were $998 \mathrm{~K}$ and $1176 \mathrm{~K}$, respectively. ${ }^{4)}$ Specimens with dimensions of $120 \times 120 \times 2.3 \mathrm{~mm}$ were austenitized at $1423 \mathrm{~K}$ for $3.6 \mathrm{ks}$ and then fully transformed to pearlite by isothermal holding at $923 \mathrm{~K}$ for $0.9 \mathrm{ks}$, resulting in a fully pearlitic structure. The fully pearlitic structure was an initial microstructure used in this study. To obtain another initial microstructure, i.e., a microduplex structure consisting of an $\alpha$ matrix and spheroidized $\theta$, the pearlitic structure was austenitized at $1043 \mathrm{~K}$ for $1.8 \mathrm{ks}$ in the $(\gamma+\theta)$ region followed by oil quenching. ${ }^{29)}$ Subsequently, tempering at $923 \mathrm{~K}$ for $1.8 \mathrm{ks}$ was conducted. ${ }^{29)}$

These ultrahigh carbon steels were friction-stir-welded using a PCBN tool in the bead-on-plate configuration. This MS100-graded PCBN tool consisted of a concave shoulder with a diameter of $14 \mathrm{~mm}$ and a tapered pin with a length of $2 \mathrm{~mm}$. The pin tapered from $5.8 \mathrm{~mm}$ at the shoulder to $4 \mathrm{~mm}$ at the pin tip. FSW was performed using a vertical milling machine fitted with servomotors and an automated control system. An argon atmosphere was introduced through a gas cup around the tool at a flow rate of $2.8 \times 10^{5} \mathrm{~mm}^{3} / \mathrm{s}\left(1 \mathrm{~m}^{3} / \mathrm{h}\right)$ to minimize surface oxidation. A $3.5^{\circ}$ tilt was applied to the welding tool during FSW. The present study produced welds in the ultrahigh carbon steel at rotational speeds of 400, 600 and $800 \mathrm{rpm}$. The travel speed of the tool was constant at $1.27 \mathrm{~mm} / \mathrm{s}$.

The microstructure of the weld was examined by scanning electron microscopy (SEM). A specimen for SEM was cut perpendicular to the welding direction and etched in a 5 vol $\%$ nitric acid +95 vol $\%$ ethanol solution. Prior $\gamma$ grain structure was observed in the cross section, which was etched in a $10 \mathrm{~g}$ picric acid $+8 \mathrm{~g}$ sodium dodecylbenzensulfonate $+200 \mathrm{ml}$ water solution at about $348 \mathrm{~K}$ for $180 \mathrm{~s}$, by optical microscopy. The average size of prior $\gamma$ grains on the optical micrograph was measured by the mean linear intercept method. The amount of retained $\gamma$ was quantified in a circle region, $5 \mathrm{~mm}$ in diameter, on weld center of the midsection by X-ray diffraction (XRD). The Vickers hardness profile was measured at the mid-thickness of the weld using a load of $98 \mathrm{~N}$.

\section{Results and Discussion}

\subsection{Microstructrural Distribution in the Weld}

SEM images of the two initial microstructures used in the present study are shown in Fig. 1. Figure 1(a) shows the initially pearlitic structure with an interlamellar spacing of about $0.15 \mu \mathrm{m}$. The thermal treatment resulted in a microduplex structure consisting of spheroidized $\theta$ particles dispersed in a fine grained $\alpha$ matrix (Fig. 1(b)). Previous studies $^{2-4)}$ have reported the $\alpha$ grain size to be less than $1 \mu \mathrm{m}$ after this thermal treatment.

Cross-sectional overviews of the welds produced at a ro-

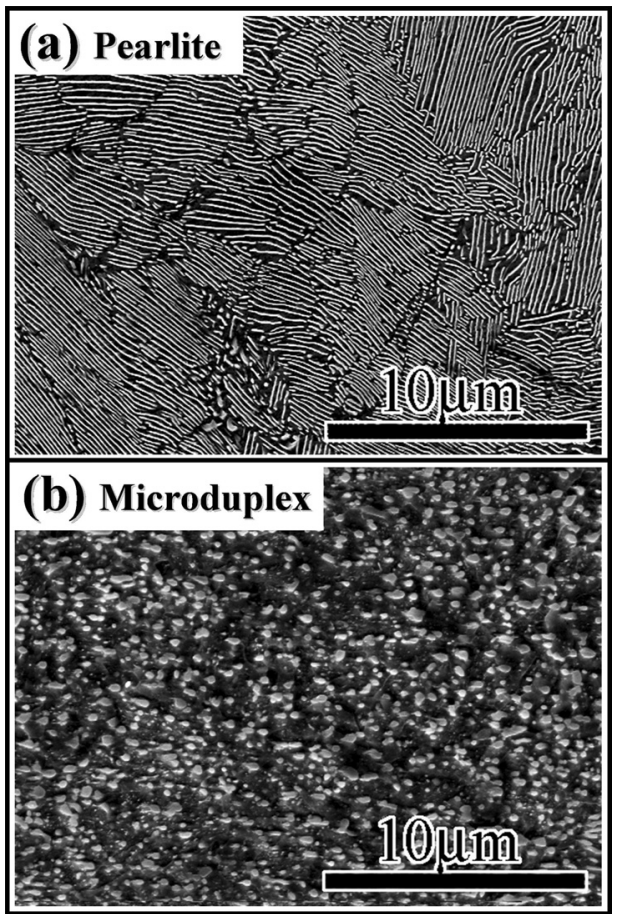

Fig. 1. SEM images of initial microstructures: (a) pearlitic structure and (b) microduplex structure.

\section{(a) Pearlite}

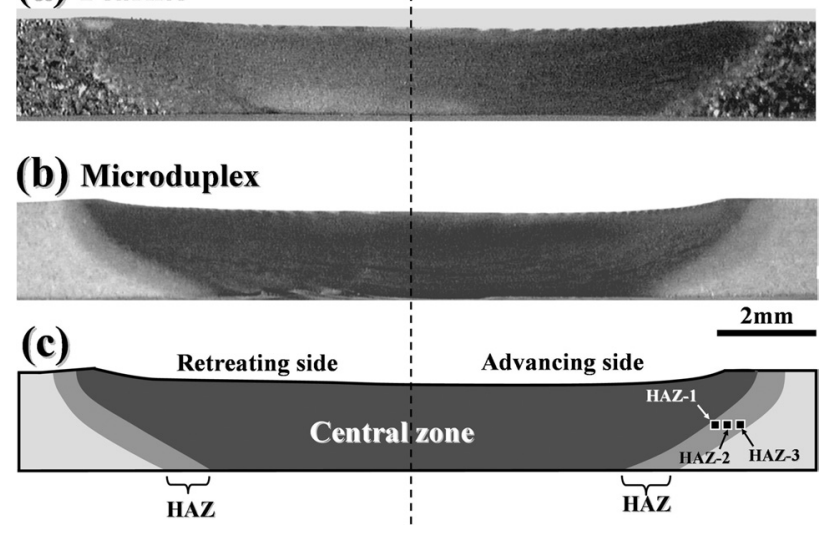

Fig. 2. Cross-sectional overview of the welds produced at rotational speed of $400 \mathrm{rpm}$ in (a) pearlitic structure and (b) microduplex structure. (c) is schematic illustration of the cross section.

tational speed of $400 \mathrm{rpm}$ in the pearlitic and microduplex structures are shown in Fig. 2. FSW successfully yielded defect-free welds in ultrahigh carbon steel at rotational speeds between 400 and $800 \mathrm{rpm}$. A region similar to the typical stir zone of the friction stir welds ${ }^{9,10)}$ was found in the weld center of all welds. This region was wider than the diameter of the tool shoulder at the top surface, as shown in Fig. 2, although the width of the stir zone was generally identical to the shoulder diameter. This result suggests that this region has microstructural features different from those of the stir zone. In the present report, this region is defined as "central zone". The effect of rotational speed on size and shape of the central zone was negligible. A heat affected zone (HAZ) was clearly observed between the central zone and the initial microstructure region. The welds consisted of three regions: the central zone, the HAZ and the initial microstructure region. 


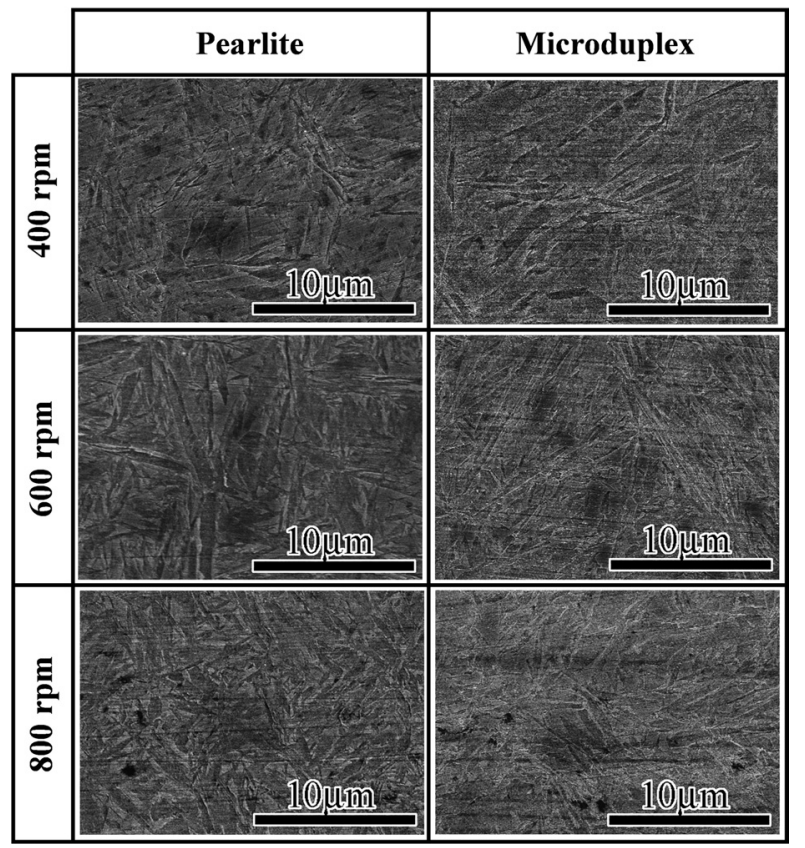

Fig. 3. SEM images of the central zones.

\subsection{Microstructure in the Central Zone}

SEM images of the central zone are shown in Fig. 3. The central zone is characterized by the martensitic structure in all welds. There is no large variation in size and morphology of the martensitic structure among all welds. The martensite packet size lay between 5 and $20 \mu \mathrm{m}$. The martensitic structure is considered to be formed by cooling from the $\gamma$ stable temperature, i.e., temperatures higher than the $\mathrm{A}_{\mathrm{cm}}$ in the equilibrium state, during FSW. It is likely that the temperature exceeds the $A_{c m}$ of this steel $(1176 \mathrm{~K})$ during FSW because some previous papers ${ }^{20,23,30)}$ have reported the maximum temperature to be higher than $1373 \mathrm{~K}$ during FSW of steels using $\mathrm{W}$ and PCBN tools. The microstructural evolution during FSW may be as follows. The initial microstructure is fully transformed to the $\gamma$ singlephase structure during the heating cycle of FSW and then transformed to the martensite during the cooling cycle due to high hardenability of the $1.0 \% \mathrm{C}$ steels. ${ }^{31,32)}$

It is well known that the martensite finish temperature, $\mathrm{M}_{\mathrm{f}}$, is below room temperature in steels containing $\mathrm{C}$ higher than $0.6 \mathrm{wt} \%{ }^{31,32)}$ Therefore, the $\gamma$ structure cannot transform to martensite completely in ultrahigh carbon steel during FSW, i.e., $\gamma$ is retained in the martensitic structure. The effect of rotational speed on the retained $\gamma$ content at the weld center in the microduplex structure quantified by XRD is summarized in Fig. 4. Retained $\gamma$ was detected in all welds and increased with increasing rotational speed.

Optical micrographs of the prior $\gamma$ grain structures in the central zones of the steel having the microduplex structure are presented in Fig. 5. The pearlitic structure also had roughly the same prior $\gamma$ grain structure in the central zone as the microduplex structure. All welds had the equiaxed grain structure. The effect of rotational speed on the average size of the prior $\gamma$ grains is given in Fig. 6. Although the grain size was largely scattered (Fig. 5), the average size of the prior $\gamma$ grain slightly increased with increasing rotational speed. The pearlitic structure was found to have

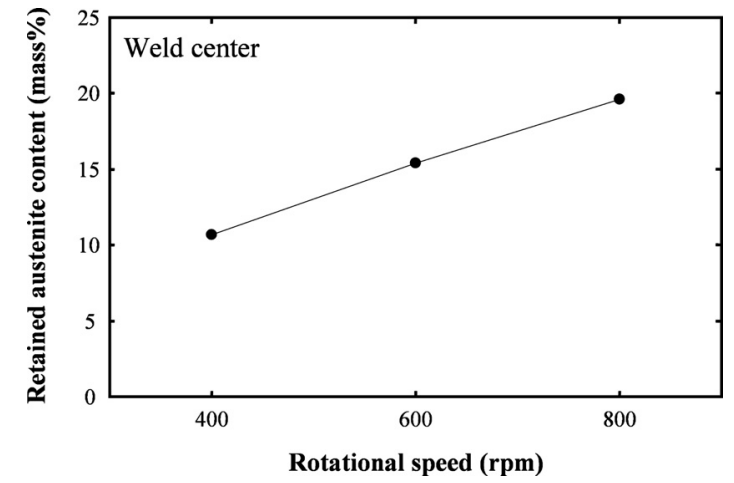

Fig. 4. Effect of rotational speed on retained $\gamma$ content at the weld center in the microduplex structure.

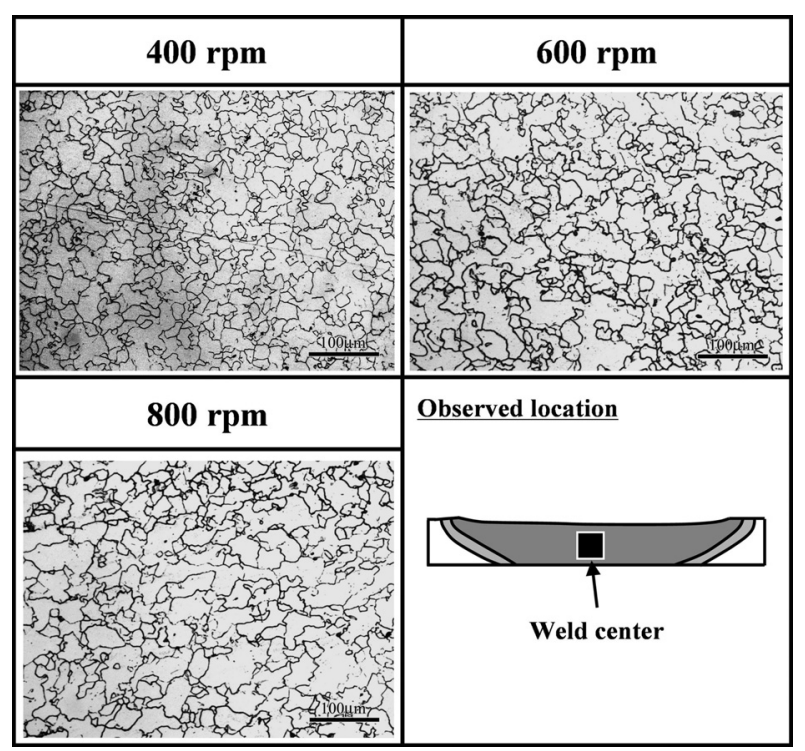

Fig. 5. Optical micrographs of the prior $\gamma$ grain structure at the weld center.

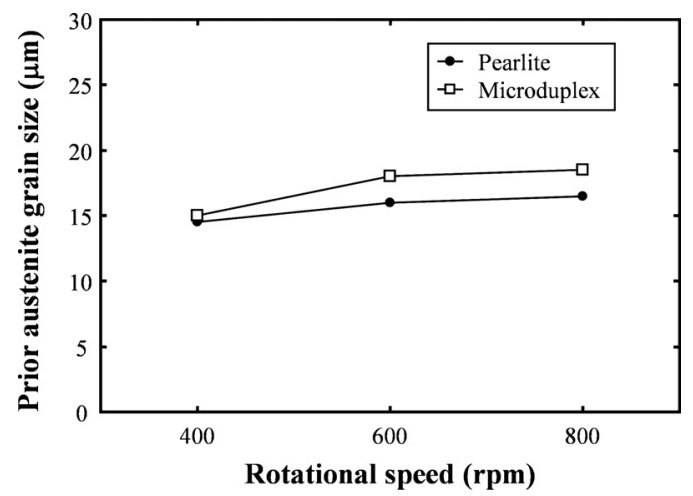

Fig. 6. Effect of rotational speed on prior $\gamma$ grain size at the weld center.

slightly smaller prior $\gamma$ grains than the microduplex structure, but the reason for this could not be clarified in the present study.

The material experiences a complex thermo-mechanical cycle during FSW. It is expected that different thermo-mechanical effects on the microstructural formation are produced at different rotational speeds. The present study suggests that material flow occurred in the $\gamma$ structure during FSW, so that the microstructural features in the $\gamma$ should depend on the rotational speeds. The retained $\gamma$ content in- 
creased with increasing rotational speed, as shown in Fig. 4. The prior $\gamma$ grain size also increased with increasing rotational speed, as shown in Fig. 6. It is well known that higher rotational speed results in higher maximum temperature during FSW of $\mathrm{Al}$ and $\mathrm{Mg}$ alloys. ${ }^{33)}$ The retained $\gamma$ content generally increases with increasing temperature in carbon steels. ${ }^{31)}$ In FSW of $\mathrm{Al}$ and $\mathrm{Mg}$ alloys, moreover, the grain size at the weld center is proportional to the heat input, i.e., higher rotational speed leads to larger grain structure. ${ }^{33,34)}$ These results suggest that the maximum temperature during FSW of the ultrahigh carbon steel also increases with rotational speed.

The thermo-mechanical effect remained in the $\gamma$ substructure, while no large difference in the martensitic structure among the welds was found. This is attributed to the fact that all welding parameters used led to both heating to within the $\gamma$ stable temperature and the sufficient cooling for martensitic transformation. Since all welds experienced martensitic transformation of the $\gamma$ single-phase structure during the cooling cycle of FSW, the $\gamma$ substructure was masked by the martensitic transformation, resulting in the negligible effect of rotational speed on the martensitic structure in the central zone.

Cui et al. ${ }^{19)}$ have reported that the martensitic transformation occurs in the carbon steels during FSW at the high travel speeds. The $0.5 \% \mathrm{C}$ steel experienced the martensitic transformation at the rotational speed of $400 \mathrm{rpm}$ during cooling cycle of FSW when the travel speed was higher than $0.42-0.83 \mathrm{~mm} / \mathrm{s}(25-50 \mathrm{~mm} / \mathrm{min})$. Since the hardenability increases with carbon content in the carbon steels, the martensitic transformation would occur in the $1.0 \% \mathrm{C}$ steels during FSW even if the travel speed is lower than $0.42 \mathrm{~mm} / \mathrm{s}(25 \mathrm{~mm} / \mathrm{min})$, which is much lower than the travel speed used in this study $(1.27 \mathrm{~mm} / \mathrm{s})$. This situation implies that the cooling rate during FSW is enough high for the martensitic transformation in the ultrahigh carbon steel used.

\subsection{Microstructure in the $\mathrm{HAZ}$}

SEM images of the HAZs of the welds produced in the pearlitic and microduplex structures are shown in Fig. 7. Locations of HAZ-1, HAZ-2 and HAZ-3 are schematically presented in Fig. 2 The HAZ had a mixed microstructure consisting of both the initial microstructure and the martensitic one. The area fraction of the martensitic structure was continuously reduced toward the initial microstructure in the HAZ. The martensitic structure contained some spheroidized $\theta$ particles, but it seems that the amount of the spheroidized $\theta$ particles was much higher in the microduplex structure than in the pearlitic structure. In clusters with the initial microstructure existing in the HAZ, some of the lamellar $\theta$ were spheroidized in the pearlitic structure, while the spheroidized $\theta$ particles were coarsened in the microduplex structure.

As temperature increases in the ultrahigh carbon steel, the initial microstructure transforms to the $(\gamma+\theta)$ structure and then to the $\gamma$ single-phase structure, according to the $\mathrm{Fe}-\mathrm{C}$ binary phase diagram. Since the $\gamma$ transforms to the martensitic structure during cooling cycle of FSW, the microstructural distribution of the weld can be deduced by taking into account the maximum temperature of each re-

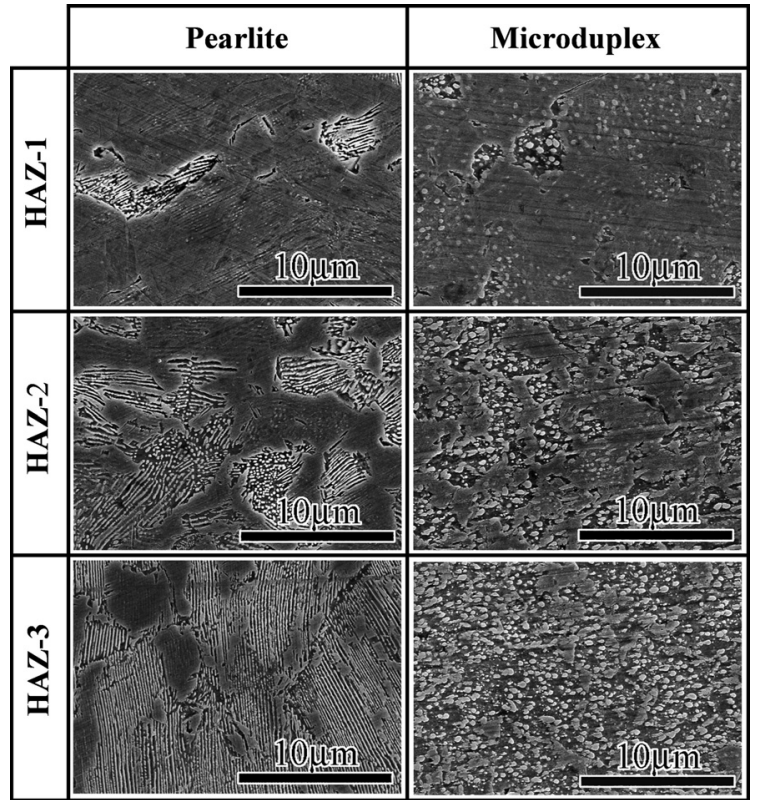

Fig. 7. SEM images of the HAZs of the welds.

gion during FSW. The mixed microstructure of the HAZ, consisting of both the initial microstructure and the martensitic structure with some spheroidized $\theta$ particles, should be formed by cooling of the mixed microstructure consisting of the $(\alpha+\theta)$ and $(\gamma+\theta)$ structures. Since it is suggested that the central zone was heated to within the $\gamma$ stable temperature during FSW, a region consisting of the $(\gamma+\theta)$ structure at the maximum temperature should exist between the central zone and the HAZ. This region should have the martensitic structure containing some spheroidized $\theta$ particles. A previous study ${ }^{29)}$ showed that this microstructure was located inside the central zone near the border between the central zone and HAZ.

The martensitic structure of the HAZ contained some undissolved $\theta$ particles. It seems that the amount of the undissolved $\theta$ particles was much higher in the microduplex structure. This result may be explained by the thermal stability of the $\theta$ particles. It is known that $\mathrm{Cr}$ is soluble in the $\theta$ in $\mathrm{Cr}$-containing steels. ${ }^{32)}$ Liu et al. ${ }^{35)}$ have shown that the $\mathrm{Cr}$ content of the $\theta$ increases with the heating time and that longer heating is required for dissolution of the $\mathrm{Cr}$-enriched $\theta$. It is likely that the spheroidized $\theta$ particles in the microduplex structure have higher $\mathrm{Cr}$ content than the lamellar $\theta$ in the pearlitic structure because the microduplex structure was produced by additional thermal processing of the pearlitic structure. This situation suggests that the thermal stability of the $\theta$ would be higher in the microduplex structure, which would cause the difference in the amount of the undissolved $\theta$ in the HAZ.

\subsection{Hardness Profile}

Hardness profiles of the welds are shown in Fig. 8. The pearlitic structure exhibits a hardness of about $320 \mathrm{HV}$, while the hardness of the microduplex structure is around $300 \mathrm{HV}$. FSW raises the hardness in the central zone significantly, the central zone having an average hardness of about $850 \mathrm{HV}$, regardless of the initial microstructure. There is no large variation in hardness profile among the welds produced at the different rotational speeds. In the HAZ, the 


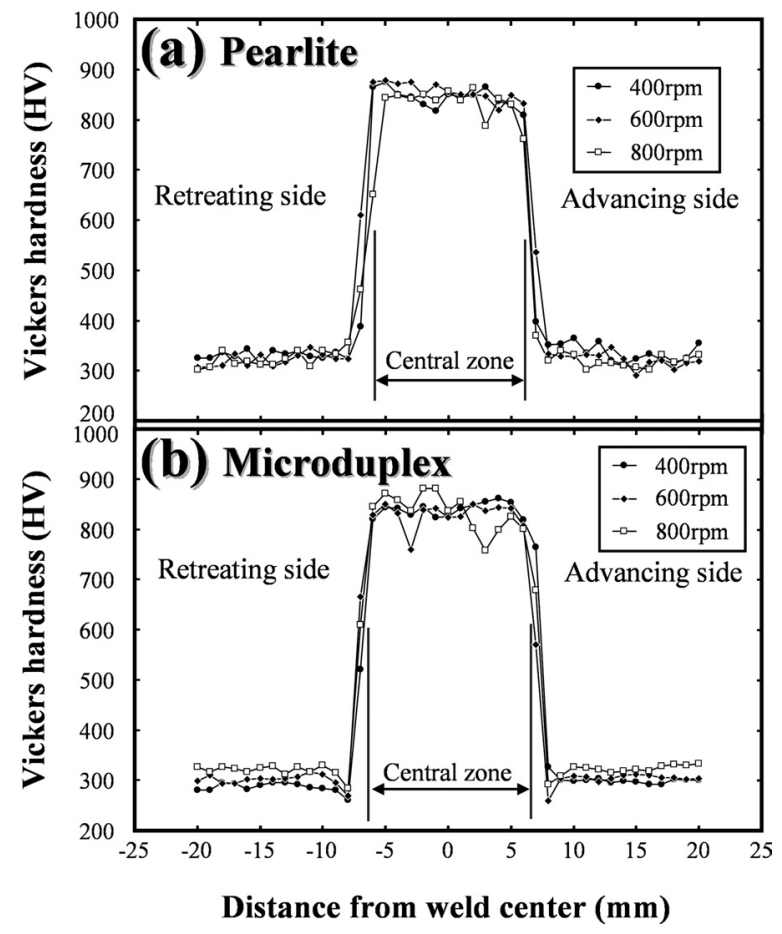

Fig. 8. Hardness profiles of the welds.

hardness steeply varied from 300-320 HV in the initial materials to $850 \mathrm{HV}$ in the central zone. It is noted that only the microduplex structure experiences the slight hardness reduction in the HAZ near the initial microstructure region (Fig. 8(b)), while there is no hardness reduction in the welds produced in the pearlitic structure (Fig. 8(a)).

It is well known that the hardness of the martensitic structure mainly depends on the carbon content. ${ }^{31,32)}$ Hardness of the martensitic structure formed in $1.0 \% \mathrm{C}$ steels has been reported to be about $850 \mathrm{HV}^{31,32)}$ which is roughly the same as that in the central zone. Cui et al. ${ }^{19)}$ have shown that the hardness in the weld depends on the martensite fraction and the hardness of the martensite in carbon steels when the martensite is formed. This situation suggests that the high hardness in the central zone can be attributed to the martensitic structure. In the HAZ, the microstructure continuously varied from the initial microstructure to the martensitic structure due to the change of the ratio of the two microstructures, and a steep transition of hardness was found. The effect of the area fraction of martensite on hardness in the HAZ is summarized in Fig. 9. The hardness exhibits roughly a linear relationship with the area fraction of martensite. This result means that the hardness can be mainly explained by the area fraction of martensitic structure in the weld.

A reduction of hardness was found in the HAZ near the initial microstructure region in only the microduplex structure. This can be explained by the change in size and morphology of the $\theta$ in the HAZ during FSW, i.e., some of the lamellar $\theta$ in the pearlitic structure was spheroidized, while the spheroidized $\theta$ particles in the microduplex structure grew. The growth of the spheroidized $\theta$ particles may cause a reduction of hardness in the welds produced in the microduplex structure.

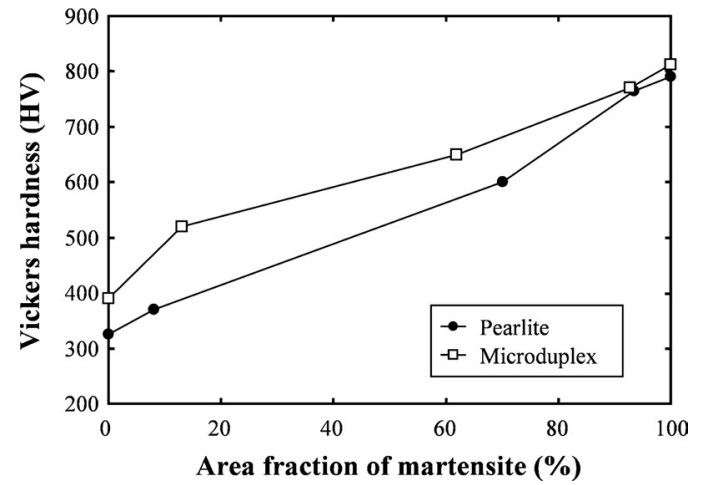

Fig. 9. Relationship between Vickers hardness and area fraction of martensite in the HAZ

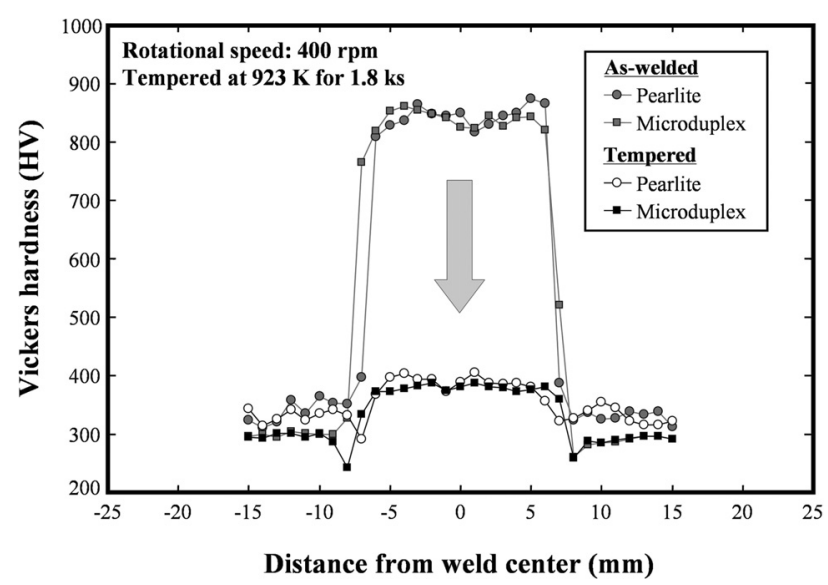

Fig. 10. Effect of tempering on hardness profiles of the welds.

\subsection{Tempering of the Weld}

FSW successfully produced defect-free welds in the ultrahigh carbon steel, but due to the martensitic structure produced in the central zone, the weld was brittle. To improve the mechanical properties of the central zone, the subsequent tempering at $923 \mathrm{~K}$ for $1.8 \mathrm{ks}$ was applied to the welds. Hardness profiles of the tempered welds produced at a rotational speed of $400 \mathrm{rpm}$ are shown in Fig. 10. Hardness was reduced from 850 to $390 \mathrm{HV}$ in the central zone. Additionally, the pearlitic structure as well as the microduplex structure experienced a slight reduction of the hardness in the HAZ, which may be attributed to the growth of the $\theta$ during tempering. There was no large variation in hardness in the other regions. SEM observation for the tempered welds showed that the $\theta$ precipitation occurred at the prior $\gamma$ grain boundary, martensite block and packet boundaries in the martensitic structure of the central zone, as shown in Fig. 11. This study showed that a defect-free weld with good mechanical properties can be obtained in ultrahigh carbon steels by FSW and subsequent tempering.

\section{Conclusions}

Ultrahigh carbon steel having two different initial microstructures was friction stir welded at different rotational speeds using a PCBN tool. FSW produced defect-free welds in the ultrahigh carbon steels at all rotational speeds used. All welds exhibited high hardness, which was characterized by a martensitic structure containing $10-20 \%$ re- 


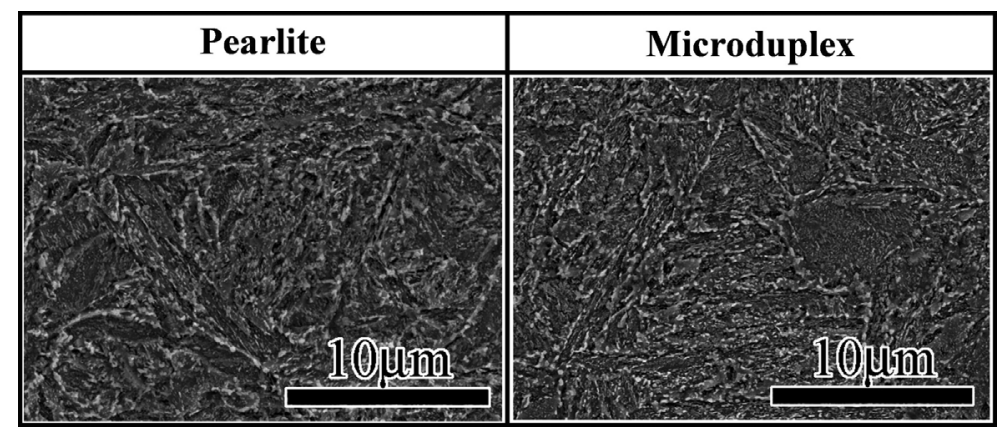

Fig. 11. SEM images of the tempered central zone.

tained $\gamma$, in the weld center. The effect of rotational speed and initial microstructure on the martensitic structure was negligible, but the amount of the retained $\gamma$ and the prior $\gamma$ grain size in the weld center increased with rotational speed. The pearlitic structure did not contain any softened regions throughout the as-welded weld, while hardness reduction was found in the HAZ of the microduplex structure. Evolution of these microstructures was reasonably explained by the FSW process, the thermal stability of the initial microstructure and the solid-state transformation during the cooling cycle of FSW.

\section{Acknowledgement}

The authors are grateful to Mr. A. Honda for technical assistance and acknowledge Mr. E. Nakanishi, Mr. K. Suzuki and Nissan Motors for providing the PCBN tool. They also wish to thank Prof. T. W. Nelson, Mr. C. J. Sterling and Mr. R. J. Steel, Brigham Young University and MegaStir Technologies for producing the friction stir welds and acknowledge Dr. T. Shiraga, Dr. K. Tomita and Mr. Y. Tamai for the prior $\gamma$ grain observation and retained $\gamma$ content analysis. The Iron and Steel Institute of Japan Research Promotion Grant is gratefully acknowledged. A part of this study was financially supported by the Japanese Ministry of Education, Science, Sports and Culture with a Grant-in-Aid from the Global COE program of the Materials Integration International Center for Education and Research at Tohoku University.

\section{REFERENCES}

1) M. Carcí, A. Fernández-Vicente, O. A. Ruano and O. D. Sherby: Mater. Sci. Technol., 15 (1999), 1087.

2) K. Tsuzaki, E. Sato, S. Furimoto, T. Furuhara and T. Maki: Scr. Mater, 40 (1999), 675.

3) T. Furuhara, E. Sato, T. Mizoguchi, S. Furimoto and T. Maki: Mater. Trans., 43 (2002), 2455.

4) T. Maki and T. Furuhara: Mater. Sci. Forum, 426-432 (2003), 19.

5) K. Tamaki, H. Kawakami and J. Suzuki: Q. J. Jpn. Weld. Soc., 20 (2002), 266.

6) S. Kou: Welding Metallurgy, John Wiley \& Sons, New York, (1987).

7) Welding and Joining Handbook, 2nd ed., Jpn. Weld. Soc., Maruzen, Tokyo, Japan, (2003)

8) W. M. Thomas, E. D. Nicholas, J. C. Needham, M. G. Murch, P. Templesmith and C. J. Dawes: International Patent Application No. PCT/GB92/02203.

9) R. S. Mishra and Z. Y. Ma: Mater. Sci. Eng. R, 50 (2005), 1.
10) Friction Stir Welding and Processing, ed. by R. S. Mishra and M. W. Mahoney, ASM Int., Materials Park, Ohio, (2007).

11) M. W. Mahoney, C. G. Rhodes, J. G. Flintoff, R. A. Spurling and W. H. Bingel: Metall. Mater. Trans. A, 29A (1998), 1955.

12) S. H. C. Park, Y. S. Sato and H. Kokawa: Metall. Mater. Trans. A, 34A (2003), 987.

13) Y. S. Sato, H. Kokawa, M. Enomoto and S. Jogan: Metall. Mater. Trans. A, 30A (1999), 2429.

14) J.-Q. Su, T. W. Nelson, R. Mishra and M. Mahoney: Acta Mater, 51 (2003), 713.

15) K. Oh-Ishi and T. R. McNelley: Metall. Mater. Trans. A, 35A (2004), 2951.

16) C. D. Sorensen: Proc. 14th Int. Offshore and Polar Eng. Conf. (ISOPE 2004), Vol. 4, ISOPE, Cupertino, California, (2004), 8.

17) H. Fujii, L. Cui, N. Tsuji, M. Maeda, K. Nakata and K. Nogi: Mater. Sci. Eng. A, A429 (2006), 50.

18) L. Cui, H. Fujii, N. Tsuji and K. Nogi: Scr. Mater, 56 (2007), 637.

19) L. Cui, H. Fujii, N. Tsuji, K. Nakata, K. Nogi, R. Ikeda and M. Matsushita: ISIJ Int., 47 (2007), 299.

20) T. J. Lienert, W. L. Stellwag, Jr., B. B. Grimmett and R. W. Warke: Weld. J., 82 (2003), 1s.

21) A. P. Reynolds, W. Tang, M. Posada and J. DeLoach: Sci. Technol. Weld. Joining, 8 (2003), 445.

22) A. Ozekcin, H. W. Jin, J. Y. Koo, N. V. Bangaru and R. Ayer: Int. J. Offshore Polar Eng., 14 (2004), 284.

23) S. H. C. Park, Y. S. Sato, H. Kokawa, K. Okamoto, S. Hirano and M. Inagaki: Scr. Mater, 49 (2003), 1175.

24) S. H. C. Park, Y. S. Sato, H. Kokawa, K. Okamoto, S. Hirano and M. Inagaki: Scr. Mater, 51 (2004), 101.

25) A. P. Reynolds, W. Tang, T. Gnaupel-Herold and H. Prask: Scr. Mater., 48 (2003), 1289.

26) S. H. C. Park, Y. S. Sato, H. Kokawa, K. Okamoto, S. Hirano and M. Inagaki: Sci. Technol. Weld. Joining, 10 (2005), 550.

27) Y. S. Sato, T. W. Nelson and C. J. Sterling: Acta Mater, 53 (2005), 637.

28) Y. S. Sato, T. W. Nelson, C. J. Sterling, R. J. Steel and C.-O. Pettersson: Mater. Sci. Eng. A, A397 (2005), 376.

29) Y. S. Sato, H. Yamanoi, H. Kokawa and T. Furuhara: Scr. Mater, 57 (2007), 557.

30) W. M. Thomas, P. L. Threadgill and E. D. Nicholas: Sci. Technol. Weld. Joining, 4 (1999), 365.

31) G. E. Totten and M. A. H. Howes: Steel Heat Treatment Handbook, Marcel Dekker, New York, (1997).

32) R. W. K. Honeycombe and H. K. D. H. Bhadeshia: Steels Microstructure and Properties, 2nd ed., Edward Arnold, London, (1995).

33) Y. S. Sato, M. Urata and H. Kokawa: Metall. Mater. Trans. A, 33A (2002), 625.

34) Y. S. Sato, H. Watanabe and H. Kokawa: Sci. Technol. Weld. Joining, 12 (2007), 318

35) Z.-K. Liu, L. Höglund, B. Jönsson and J. Ågren: Metall. Trans. A, 22A (1991), 1745. 